\title{
A study of reproducibility of kinesiology tape applications: review, reliability and validity
}

\author{
Francisco Selva ${ }^{1 *}$ D, Alberto Pardo ${ }^{2}$, Xavier Aguado $^{3}$, Ignacio Montava ${ }^{4}$, Luis Gil-Santos ${ }^{5}$ and Carlos Barrios ${ }^{5}$
}

\begin{abstract}
Background: Literature addressing the mechanical properties of kinesiology tape is quite scarce. There are no studies which focus on the mechanical characteristics of kinesiology tape, its mechanical properties, nor its adherence following the ISO international standard test methods for tape elongation.

Methods: This study quantified the mechanical characteristics of 380 samples of kinesiology tape from 19 different brands and in 4 different colors using a dynamometer. Mechanical testing was controlled by UNE EN ISO 13934-1.

Results: Significant differences were found between tape brands in terms of grammage, maximum force tenacity, work, pre-elongation and percentage elongation $(P<.001)$. Regarding kinesiology tape color, statistically significant differences were found between tape brands in terms of grammage, maximum force and tenacity $(P<.001)$, work and pre-elongation $(P<.05)$. When adherence was studied, statistically significant differences were found between tape brands in terms of maximum force and work $(P<.001)$.

Conclusions: The different kinesiology tapes presented different behaviors with regard to rupture and removal when applied to skin in dry state, wet state and after being submerged in artificial acidic sweat solution. Therefore, different kinesiology tape brands will produce different levels of strain even though the same elongation is used. Depending on the characteristics (body dimensions) and properties (skin elongation) of each subject in the sample, bandages with different elongations must be applied to achieve the same strain in all of the tapes and therefore produce the same effect. The absence of these data at this time limits the reliability of previous clinical studies, makes comparing their findings impossible and presents new challenges for research in this field.
\end{abstract}

Keywords: Mechanical processes, Strain, Elongation, Adherence, Injury prevention

\section{Background}

Recent years have seen significant developments in bandaging techniques, above all with the appearance of kinesiology tape (KT). These tapes have a plain weave structure and, thanks to their elastane content, allow for longitudinal stretch.

Some authors credit KTs with effects such as the improvement of somatosensory stimulation and an increase in mechanoreceptive and proprioceptive impulses which cause various responses such as the facilitation or

\footnotetext{
* Correspondence: info@franciscoselva.com

${ }^{1}$ Department of Physiotherapy, Own Master in evaluation, physiotherapy and reconditioning in sports science, University of Valencia, Calle Gascó Oliag 3, 46010 Valencia, Spain

Full list of author information is available at the end of the article
}

inhibition of muscle activation [1-3]. However, there is insufficient clinical evidence to support these claims $[4,5]$.

The application of KT has become a popular treatment among athletes, although its real effects are still being investigated [6].

Nevertheless, various authors encourage the use of KT for all athletes as a way to prevent and treat musculoskeletal injuries [7-10] or control static and dynamic posture $[9,11]$.

There is no clear consensus regarding the key aspects of KT application methodology, such as the percentage elongation to be used [5]. Notwithstanding Lim's [5] results regarding percentage elongation, their review suggests that the effect size for pain reduction was lower

(c) The Author(s). 2019 Open Access This article is distributed under the terms of the Creative Commons Attribution 4.0 International License (http://creativecommons.org/licenses/by/4.0/), which permits unrestricted use, distribution, and reproduction in any medium, provided you give appropriate credit to the original author(s) and the source, provide a link to the Creative Commons license, and indicate if changes were made. The Creative Commons Public Domain Dedication waiver (http://creativecommons.org/publicdomain/zero/1.0/) applies to the data made available in this article, unless otherwise stated. 
when the studies applied more tension and left the tape in situ longer.

Consequently, KT applications cannot be reliably reproduced. According to the analysis in published systematic reviews [12-16], studies into KT present either low or very low methodological quality when assessed using the Grading of Recommendations Assessment, Development and Evaluation system (GRADE) adopted by the Cochrane Collaboration; as a result, there is currently no clinically significant evidence to support the use of KT as a therapeutic tool [17]. GRADE methodology is not a definitive fixed guide but rather provides suggestions regarding how to approach the literature, developing an optimal system of rating quality of evidence and strength of recommendations for clinical practice guidelines [18].

Even though extensive effort has been invested in evaluating the efficacy of $\mathrm{KT}$, there is still a dearth of attempts to collate the findings from individual studies to determine the effects of $\mathrm{KT}$ application on pain and disability and, if these effects are found, their magnitude [5].

It is necessary to define standardized methodological criteria so to that effects of KT can be demonstrated. [19, 20].

Specific research studies, such as that by Pamuk and Yucesoy [21] deem the application of KT to be effective. Magnetic resonance (MR) imaging has been used to provide a reliable representation of tissue deformation, including changes in the length of muscle fibers and the direction of this change after the application of KT. The lack of homogeneity in the deformation of muscle fibers produced by KT strain indicates the occurrence of epimuscular myofascial force transmission. Accordingly, changing the level of tension the KT applies to the skin can transmit different levels of force directly to muscle tissues, either to stimulate or inhibit. Pamuk and Yucesoy [21] produced a detailed evaluation of the local tissue deformation occurring acutely under the mechanical load imposed by the application of KT. Their results show local tissue deformations produced by the effects of KT application, confirming that $\mathrm{KT}$ also affects non-targeted tissues and sustaining the role of a neuro-mechanical coupling in the entire limb.

Although these studies show that kinesiology tape is effective, the specific action mechanisms of KTs and their real physiological effects remain unknown [19-21].

As a result, defining the methodological characteristics of the application of kinesiology tape is deemed to be a priority.

As they do not use an agreed methodology, positive results in previous $\mathrm{KT}$ studies may be attributed to placebo effects, too [19].

Two studies have been published regarding the mechanical properties of KT $[22,23]$. The first, by Fernández
Rodríguez et al. [22], included 11 tapes from 4 brands which were analyzed and compared in terms of maximum percentage stretch, maximum force applied before rupture, thickness, density and grammage. The authors postulate that there are differences between the mechanical properties of the various brands and colors of $\mathrm{KT}$ but do so without completing a statistical analysis of their results.

The second study, by Matheus et al. [23], found significant differences between 50 specimens of KT (10 samples from 5 different brands or manufacturers), testing the maximum strain, maximum deformation, maximum load, and rigidity using an EMIC universal testing machine (model DL 10.000). They also found significant differences in adherence force when removing KT specimens from a metal plate.

There are no studies into the characteristics of KT, its mechanical properties, maximum adherence force and work done when removing it from skin in dry, wet, or sweaty state (the state of the skin will affect the tape's adherence) which follow ISO international standard test methods for bandage stretching [24]. Following standard test methodology is necessary to enable KT applications to be reproduced.

The reproducibility of the effect of KTs is crucial in clinical settings. It is possible that the effect the application produces on the tissues may differ depending on the mechanical properties of each tape. Perhaps the absence of any effect from the application of KT reported in previous studies is related to the characteristics of the different KTs and the application time.

Consequently, to repeatedly obtain a certain level of strain there would have to be no variation in the properties of the tape. The reproducibility of the effects of KT has not been studied with sufficient rigor until now.

Our objective was to determine if KTs have different characteristics and mechanical properties in terms of rupture and adherence in dry state, wet state and after being submerged in artificial acid sweat solution. The tapes studied were grouped by color and brand to standardize the KT applications. This analysis will facilitate the reproducibility and standardization of KT application strain through knowledge of the different elongation percentages of each KT, thereby facilitating methodologically correct tape applications to achieve reproducible effects and so determine the limitations of KT.

\section{Methods}

Specimens

The characteristics and mechanical rupture properties, as well as the adherence properties of 380 specimens from 19 brands of KT were analyzed. Rolls of tape in four different colors (reference 1: blue; reference 2: black; reference 3: beige; reference 4: red) from each 
brand were tested. All the KTs were new, unused and unopened.

\section{Study design}

A Z005 dynamometer (Zwick Roell, Ulm, Germany) (Fig. 1), controlled by the V10.11 ZwickTestXpert software, was used for the mechanical testing. Before beginning each test, the dynamometer software requested the grammage of each specimen to adjust the preload. A 5 $\mathrm{cm}^{2}$ sample of each KT was used for this purpose. The ISO standard practice for atmosphere conditioning and physical testing of textiles [24] was followed, as was the ISO standard practice for preconditioning and conditioning the tests [25].

ISO standard testing practice [26] specifies a reliable procedure to determine the maximum force and elongation at maximum force of textiles using the strip method.

Following ISO standard testing practice [24], the specimens were $300 \mathrm{~mm}$ in length and $50 \mathrm{~mm}$ in width. They were stretched at a constant rate of extension until rupture occurred. The mean value of the data obtained was calculated.

The characteristics tested were: the elongation under which the tape adhered to the backing paper or pre-elongation capacity, and grammage (weight in $\mathrm{g} / \mathrm{cm}^{2}$ ).

The mechanical properties tested were: maximum force $(\mathrm{N}$ or $\mathrm{Kg})$; tenacity $\left(\mathrm{kg} / \mathrm{mm}^{2}\right)$; work $(\mathrm{kg} / \mathrm{mm})$; elongation without paper (\%).

To evaluate the adherence force and the work done to remove the KT from skin, pieces of untanned sheepskin, $50-\mathrm{mm}$ wide by $80-\mathrm{mm}$ long, were included in the test. $50 \mathrm{~mm}$ of one end of the KT sample were stuck to the

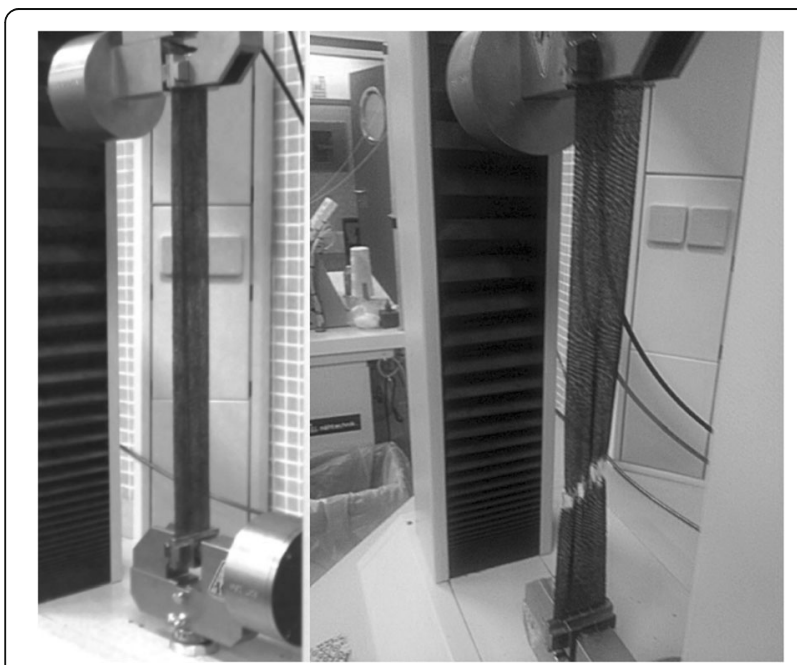

Fig. 1 Dynamometer Zwick/Roell. model Z005 (Ulm. Germany) during the strain test of one black tape. The appearance of white marks in the tape indicates its immediate breakage piece of skin at $0 \%$ elongation leaving $30 \mathrm{~mm}$ of skin at one end of the piece uncovered.

Subsequently, to carry out the adherence test in dry state, $20 \mathrm{~mm}$ of the uncovered skin was secured in the lower dynamometer clamp, leaving $10 \mathrm{~mm}$ of uncovered skin between the clamp and the KT. The backing paper was removed from the $\mathrm{KT}$ and, at $0 \%$ elongation, the end of the tape not adhered to the skin was secured in the upper clamp while leaving $40 \mathrm{~mm}$ of tape between the skin piece and the upper clamp. The distance between the clamps was $100 \mathrm{~mm}$ (Fig. 2).

The KT was preloaded by stretching it without removing it from the skin until $\pm 2 \mathrm{~N}$ of strain were reached. From this moment, the dynamometer began to separate the clamps, stretching the test piece until it came away from the skin.

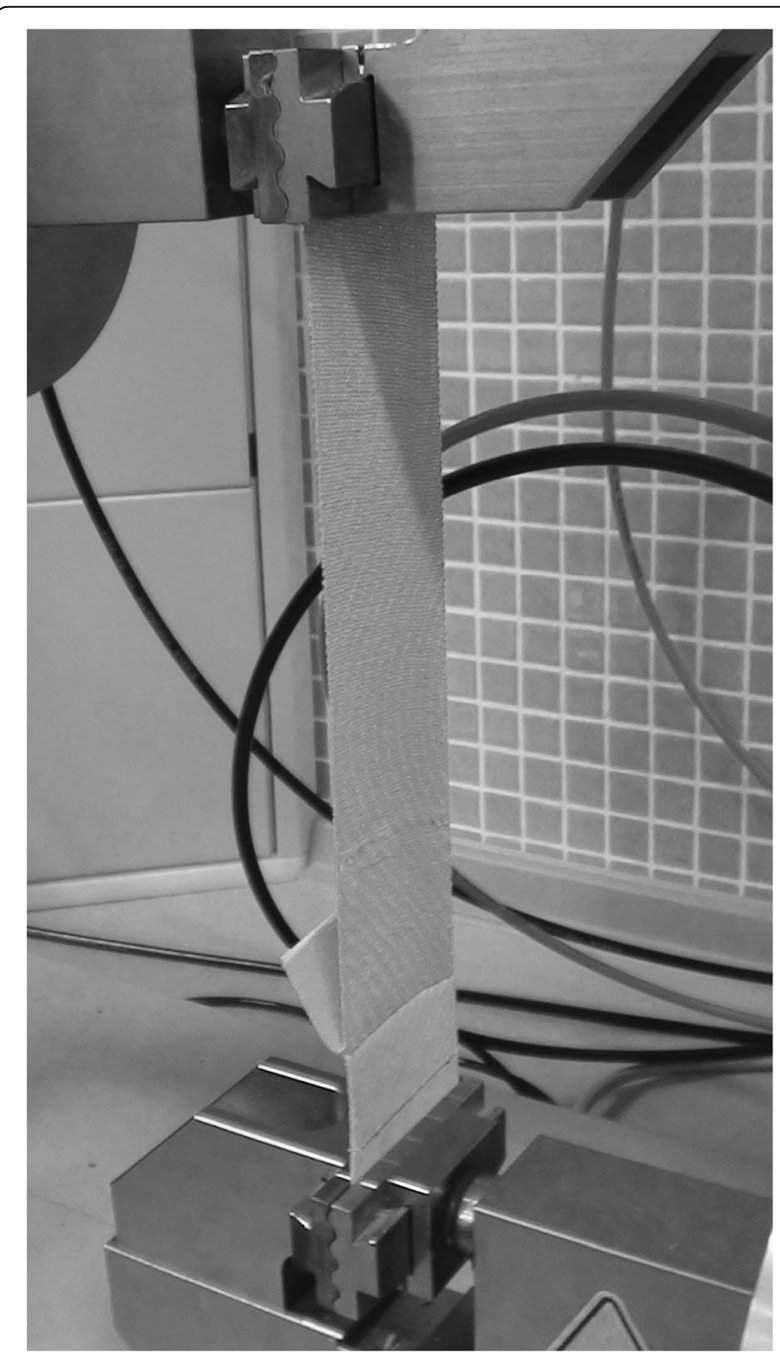

Fig. 2 Dynamometer Zwick/Roell. model Z005 (Ulm. Germany) during the adherence test of one red tape. The tape is adhered on a piece of untanned sheepskin 
To carry out the tests in wet state, water quality parameters for Grade 3 water were used, in accordance with ISO specifications for water for analytical laboratory use [27]. The water was poured into a suitable, clean, airtight vessel. Having previously stabilized the adherence force, the skin samples with attached KT were submerged in the solution for $10 \mathrm{~min}$. After this time had lapsed the previously described dynamometer methodology for testing the dry samples was repeated with the wet samples.

To carry out the tests with artificial acidic sweat, the formula for artificial acidic sweat defined in the relevant UNE standard [28] was used. Having previously stabilized the adherence force, the samples were submerged for $10 \mathrm{~min}$ in said solution. After this time, the previously described dynamometer methodology was repeated for these samples.

Components extracted from 7 black-color specimens were also analyzed by gas chromatography-mass spectrometry (GC-MS). An Agilent $5973 \mathrm{~N}$ mass spectrometer with a low resolution quadrupole analyzer was used, with an Agilent $6890 \mathrm{~N}$ gas chromatograph for capillary columns (split/splitless, pulsed split and pulsed splitless) and GC-MS interface. An Agilent 7683 Automatic Liquid Sampler and a large NIST spectroscopy database were also used. Four equally-sized pieces were cut from each of the different KTs and placed in $15 \mathrm{ml}$ of dichloromethane. The solution was agitated for $1 \mathrm{~h}$ at room temperature. $1 \mathrm{ml}$ of the solution was filtered and injected into the chromatograph.

\section{Statistical analysis}

The data were analyzed using the SPSS Statistics 20 program (IBM, Spanish version). The distribution of the data was evaluated using the Kolmogorov-Smirnov test. We also prepared descriptive statistics for each variable (mean \pm standard deviation). One-way (between the subjects) ANOVA was used for the mean differences test. The significant differences were investigated further using pairwise comparisons to control inflation of type I errors, specifically the Tukey tests. Before the analyses were carried out, the parametric assumptions such as approximate normality and homogeneity of variances, and these detection analyses, were considered not to present any impediment to the use of ANOVA. The alpha value $=0.05$ was used as the significance level and the confidence interval for the mean value was $95 \%$.

\section{Results}

\section{Rupture}

\section{Grouped by brand}

The mean values, standard deviations, and differences in the grammage of the specimens are presented in Table 1, grouped by brand. Brand was found to have a statistically significant effect based on grammage $(\mathrm{F}=13.56 ; P<.001)$. The grammage ranged from 179.1 to $230.5 \mathrm{~g} / \mathrm{m}^{2}$.
Statistically significant differences were found in all tape parameters grouped by brand: maximum force $(\mathrm{F}=14.20$; $P<.001)$, tenacity $(\mathrm{F}=14.10 ; P<.001)$, work $(\mathrm{F}=15.01 ; P$ $<.001)$, pre-elongation $(\mathrm{F}=10.05 ; P<.001)$, and percentage elongation $(\mathrm{F}=17.46 ; P<.001)$. The data are presented in Table 1.

Maximum force ranged from 12.3 to $26.0 \mathrm{~kg}$, tenacity from 0.246 to $0.520 \mathrm{~kg} / \mathrm{mm}$, work from 0.27 to $0.56 \mathrm{~kg}$ $/ \mathrm{mm}$, pre-elongation capacity from 4.4 to $10.9 \%$ and percentage elongation from 36.9 to $68.5 \%$.

Brand 8 demonstrated the greatest maximum force and tenacity, demonstrating a statistically significant difference from the other brands.

\section{Grouped by KT color}

There were significant differences in grammage $(\mathrm{F}=$ 6.50; $P<.001$ ) between colors of KT.

Statistically significant differences were found between the different colored tapes with regard to maximum force $(\mathrm{F}=15.07 ; P<.001)$, tenacity $(\mathrm{F}=15.22 ; P<.001)$, work $(\mathrm{F}=7.04 ; P<.05)$, and pre-elongation $(\mathrm{F}=12.97 ; P$ $<.05)$. There was no significant difference in percentage elongation $(\mathrm{F}=1.14 ; P>.05)$.

Black KT demonstrated the lowest maximum force capacity, tenacity and pre-elongation. Blue KT demonstrated the greatest work capacity and the greatest pre-elongation. The differences between the other colored tapes were not statistically significant. Black KTs had the highest grammage.

\section{Chemical components of the adhesive}

The results showed that the primary substances contained in and common to all the KT tested were: Cyclotrisiloxane, hexamethyl; Cyclotrisiloxane, octamethyl; Limonene/cyclohexanol and 1-hexanol. Subsequently, 58 substances were recovered which were contained in at least one of the KTs studied.

\section{Adherence in dry state Grouped by brand}

Statistically significant differences were found between tape brands in terms of maximum force $(\mathrm{F}=55.85 ; P$ $<.001)$ and work $(\mathrm{F}=10.71 ; P<.001)$.

Maximum force ranged from 0.85 to $4.31 \mathrm{~kg}(95 \% \mathrm{CI}$ : $2.11-2.29)$ and work from 0.11 to $0.60 \mathrm{~kg} / \mathrm{mm}$ (95\% CI: 0.14-0.17) (Table 2).

\section{Grouped by KT color}

A one-way ANOVA test showed no statistically significant differences between the KTs grouped by color in terms of maximum force $(\mathrm{F}=0.41 ; P>.05)$ or work $(\mathrm{F}=0.91$; $P>.05)$. Blue KT demonstrated the greatest maximum force and Tape 4 the least. Black KT demonstrated the greatest work and Red KT the least (Table 3). 


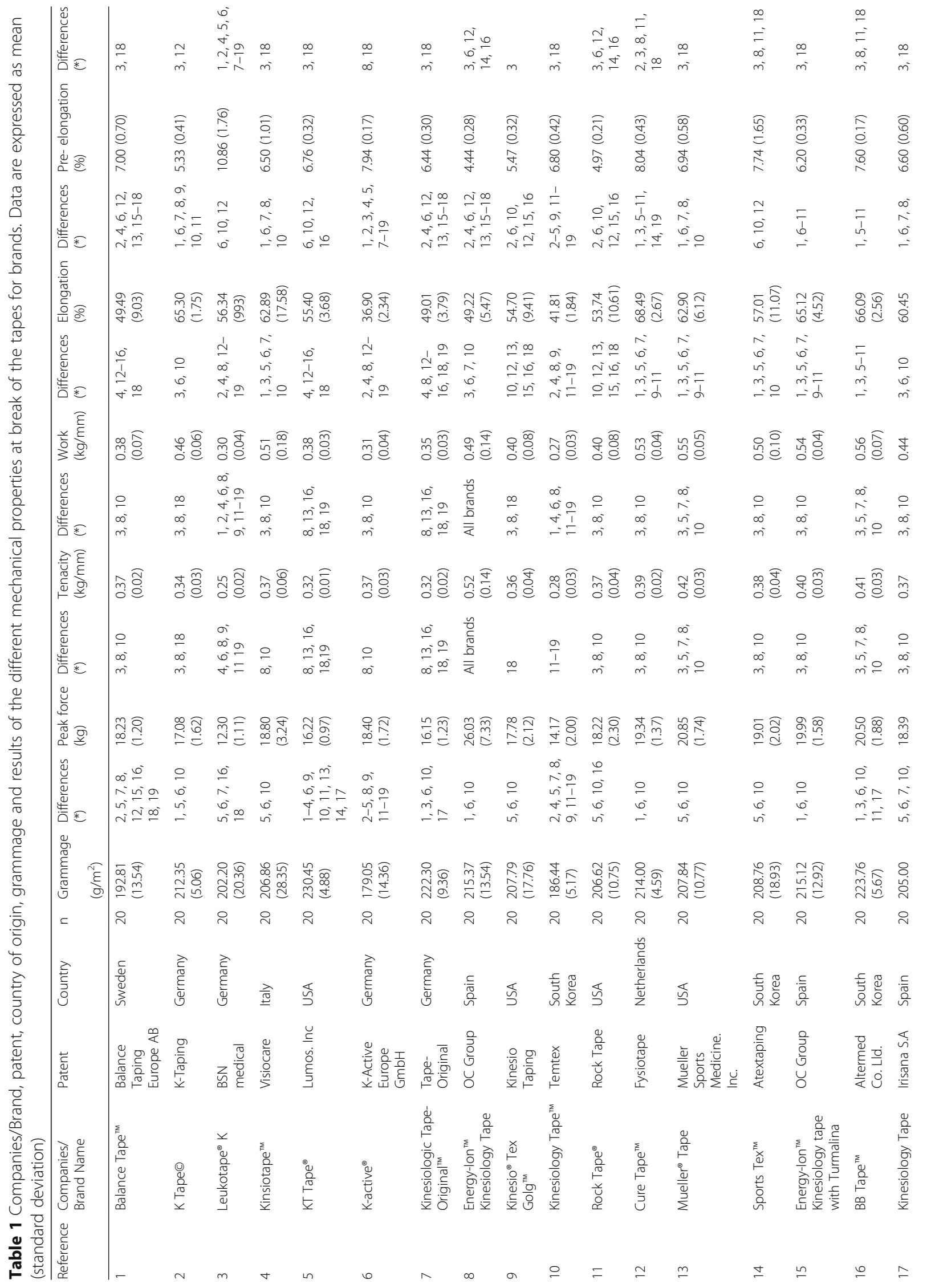




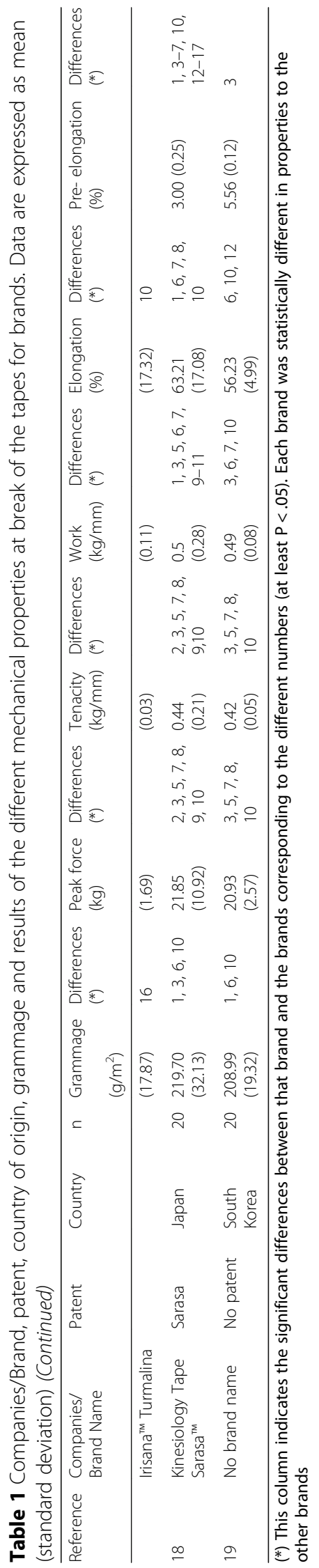




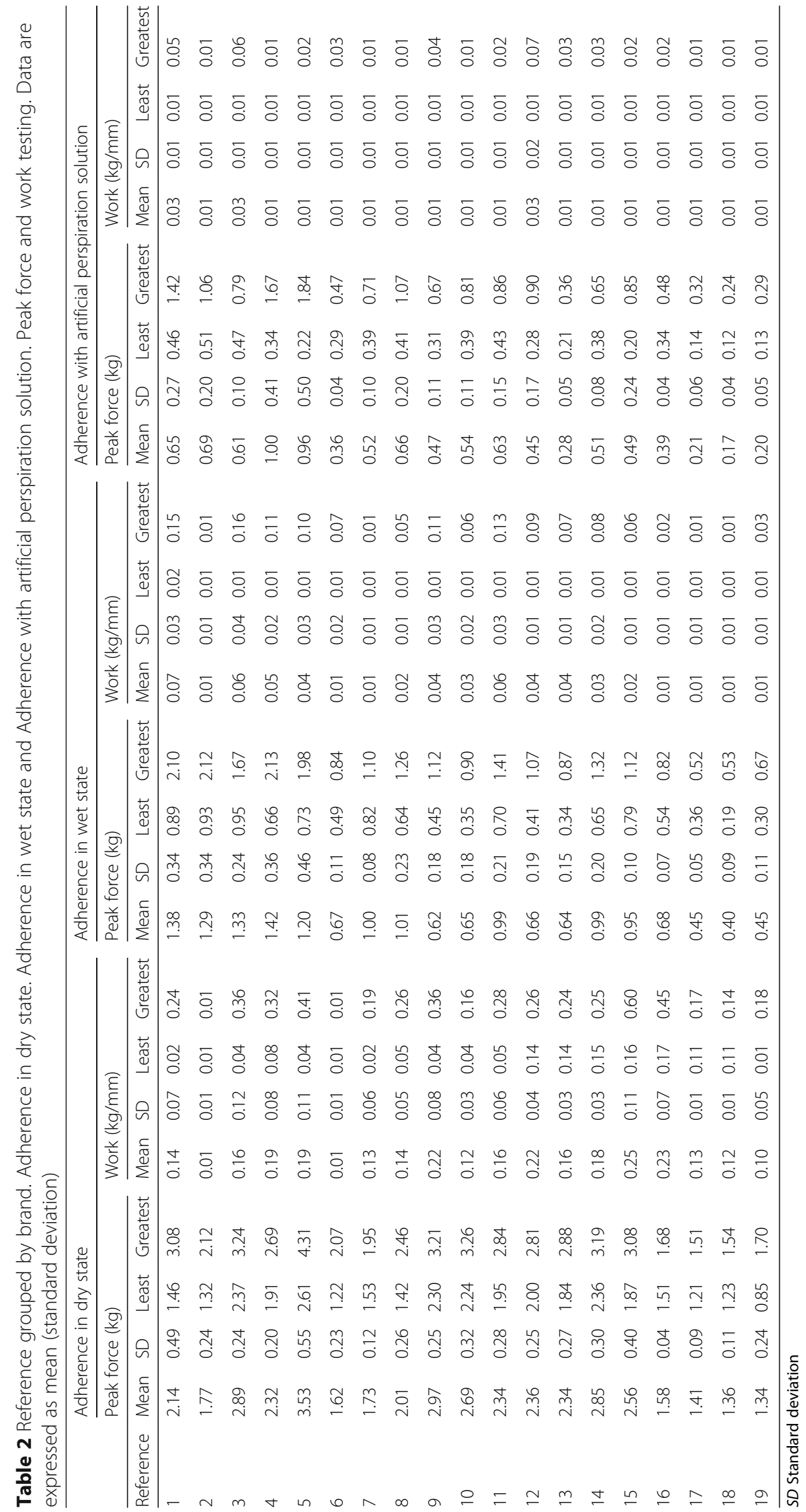




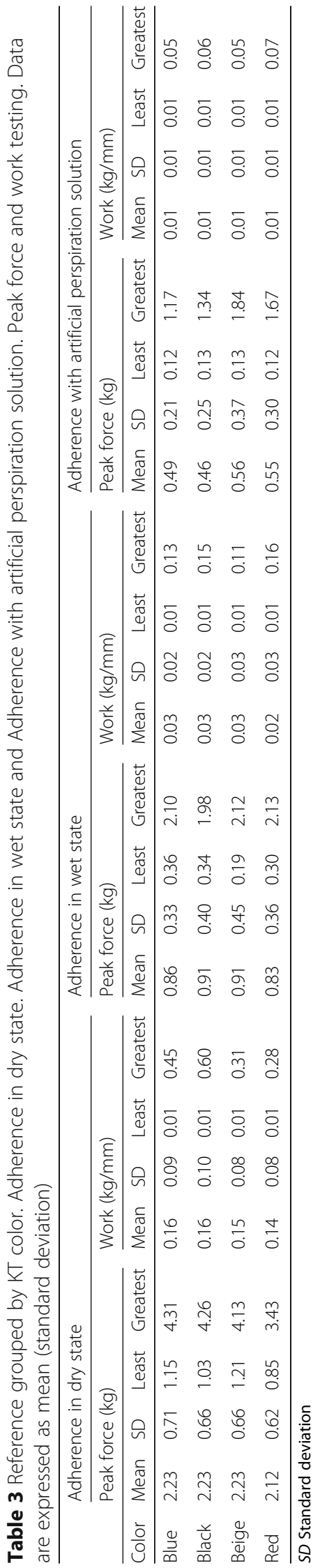




\section{Adherence in wet state Grouped by brand}

Statistically significant differences were found between the KT brands in terms of maximum force $(\mathrm{F}=25.61 ; P$ $<.001)$ and work $(\mathrm{F}=7.71 ; P<.001)$.

Maximum force ranged from 0.19 to $2.13 \mathrm{~kg}$ (95\% CI: $0.83-0.93)$ and work from 0.025 to $0.168 \mathrm{~kg} / \mathrm{mm}(95 \%$ CI: 0.029-0.037) (Table 2).

\section{Grouped by KT color}

A one-way ANOVA test showed no statistically significant differences between the KTs grouped by color in terms of maximum force $(\mathrm{F}=0.56 ; P>.05)$ or work $(\mathrm{F}=$ $0.71 ; \mathrm{P}>.05)$. Red KT demonstrated the greatest maximum force and Beige KT the least. Red KT demonstrated the greatest work and Beige $\mathrm{KT}$ the least (Table 3).

\section{Adherence with artificial perspiration solution Grouped by brand}

Statistically significant differences were found between the KT brands in terms of maximum force $(\mathrm{F}=15.39 ; P$ $<.001)$ and work $(\mathrm{F}=12.04 ; P<.001)$.

Maximum force ranged from 0.12 to $1.84 \mathrm{~kg}(95 \% \mathrm{CI}$ : $0.48-0.55)$ and work from 0.001 to $0.718 \mathrm{~kg}$ (95\% CI: 0.001-0.015) (Table 2).

\section{Grouped by $K T$ color}

A one-way ANOVA test showed no statistically significant differences between the KTs grouped by color in terms of maximum force $(\mathrm{F}=1.51 ; P>.05)$ or work $(\mathrm{F}=$ 1.08; $\mathrm{P}>.05)$. Beige KT demonstrated the greatest maximum force and Blue KT and Red KT the least. Red KT demonstrated the greatest work and Beige KT the least (Table 3).

\section{Discussion}

The objective of this study was to define the characteristics, and mechanical rupture and adherence properties of a wide variety of KT specimens. In this way, we attempt to respond to the need to define standardized and reproducible application criteria so that the effects of KTs can be specified.

In the previous studies we analyzed, the values described for the maximum elongation, expressed as a percentage of the specimen's initial elongation, ranged from 20 to $40 \%[20,29-31]$ or $55-60 \%$ [32] to $120-140 \%$ [1, 33-37], $140-150 \%$ [38] and 250 to $400 \%$ [23]. None of the 380 specimens tested reached an elongation of $100 \%$ of their initial length $(600 \mathrm{~mm})$ before rupture.

The two previous studies [22, 23] found differences between their specimens, and [23] found significant differences between the KT brands tested. This study revealed considerable variation between the different brands and colors of KT in terms of maximum force, tenacity, work, pre-elongation and percentage elongation y grammage (Table 1). Following the standard testing methodology, the grammage of each specimen must be taken and a pre-load must be carried out before each test. The previous study which used a dynamometer [23] does not mention this information and consequently the method used to extract the data remains unknown. This makes it impossible to reproduce the research and could lead to the generation of further conflicting results.

Untanned sheepskin was used to ensure that the adherence test was as reliable as possible and its results were applicable to clinical practice. The maximum adherence force and work done when removing the tape from the skin in dry state was very high, lower when the skin had been submerged in an aqueous solution, and even lower when it had been submerged in an artificial acidic sweat solution (Tables 2 and 3). Study [23] obtained far lower values using a metal plate.

Taking the maximum elongation of $4 \mathrm{KT}$ specimens (Fig. 3) as a reference, they can be seen to be at different deformation points. Tape 4 will generate lower levels of strain because $30 \%$ elongation is within the material's elastic deformation range and its flexibility means it will stretch considerably without limiting body movements. At its maximum elongation (point of rupture) the tape has lower energy absorption potential as it is in the plastic-elastic region of the stress-strain curve, tenacity is lower and, consequently, the work or total area under the curve is very large (Fig. 3). This reasoning can be considered fundamental and demonstrates that the tension produced by different tapes does vary.

We concur with Pamuk and Yucesoy [21] that the application of KT produces effects and that different applications cause different effects, but in order to specify said effects the same mechanical response must be achieved using an optimum, specific and reproducible level of tension. Achieving said mechanical response may require different elongations in different KTs. To this end the characteristics and properties of the KT used must be specified in addition to its maximum adherence force. It is also necessary to know the elongation reference used, the work done when removing the tape from the skin, the skin conditions, and the elongation of the skin to be bandaged to produce the same tension in each patient to produce the same effect $(P$ $<.05)$ without exceeding the elastic elongation of the KT both at the point of application and once the movement to be trialed has been completed.

This would facilitate the objective discovery of the different action mechanisms of KTs which could affect clinical results, as González-Iglesias et al. [39] believe.

In their literature review Morris et al. [14] only included KT studies which used the Kinesio ${ }^{\circ}$ Tex brand. 
Tape 1
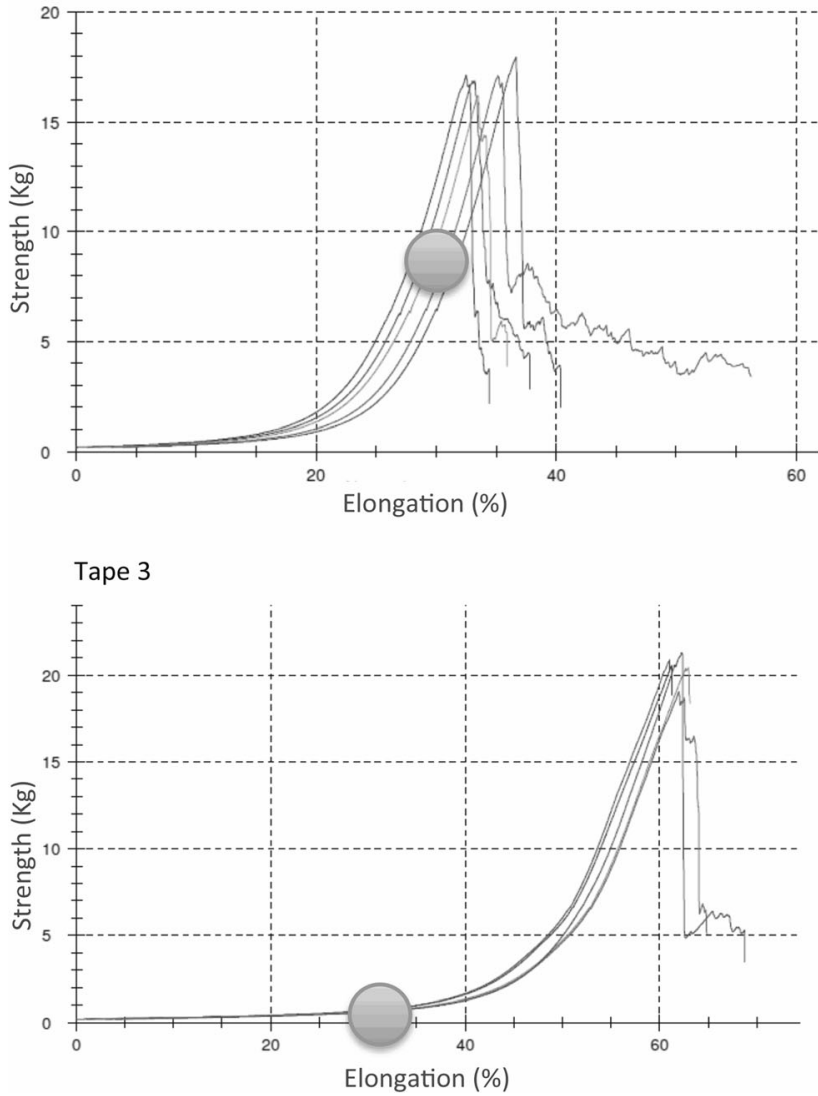

Tape 2
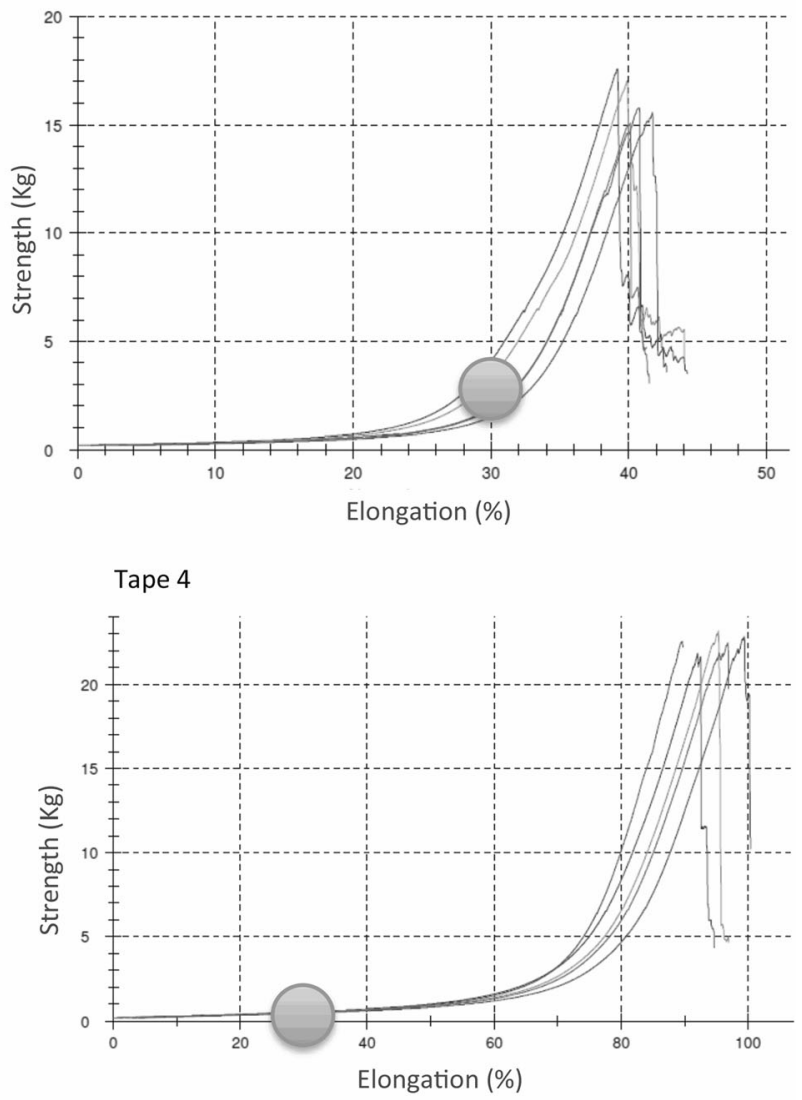

Fig. 3 Tape 1: Strain of a beige tape (reference [10]) until breakage. Maximum elongation is 33-37\%. requiring 16 to $18 \mathrm{~kg}$ of strength to breakage. Tape 2: Strain of a red tape (reference [9]) until breakage. Maximum elongation is $37-45 \%$. requiring 16 to $17 \mathrm{~kg}$ of strength to breakage. Tape 3: Strain of a blue tape (reference [11]) until breakage. Maximum elongation is 60-63\%. requiring 21 to $22 \mathrm{~kg}$ of strength to breakage. Tape 4: Strain of a black tape (reference [4]) until breakage. Maximum elongation is $94-99 \%$. requiring 23 to $24 \mathrm{~kg}$ of strength to breakage. The blue point marks the 30\% elongation of each tape

This exclusivity was to improve the accuracy of their conclusions, as they believed other brands of KT used in clinical practice were different.

It remains to be shown whether the variability in the tension and adherence of KTs changes the effect they produce during their application even when the same application metholodolgy is used for different tapes.

Our results suggest that the basic concepts of KT application are not yet complete and that studies which tried to determine the effects of $\mathrm{KT}$ are not reproducible. This may explain the disparity in the results obtained by different studies investigating the effects of KT. According to Lim's review [5], there are studies that did not report the amount of stress applied while others did not report the length of each tape used in situ.

This study is limited by testing using a uniform strain and a constant velocity. Moreover, there may be a certain degree of variability between the KTs and the different brands due to them coming from different production lots.

\section{Conclusions}

The KT specimens studied had the same structure but different chemical compositions, characteristics and mechanical properties.

The different KTs presented different behaviors with regard to rupture and removal when applied to skin in dry state, wet state and after being submerged in artificial acidic sweat solution.

If the elongation limits of each KT are unknown, many of them will produce different levels of strain even though the same elongation is used.

The absence of these data limits the reproducibility and the reliability of clinical studies using KT. Clinical studies should specify the reference used (tape length or tape elongation) to define the percentage elongation employed, something which has not been specified in studies to date.

In order for future clinical studies to be standardized and reproducible, the physiotherapist must achieve the same effect with each $\mathrm{KT}$ application, taking into account 
the reaction of its mechanical rupture and adherence properties, as well as the stretching of the skin to be bandaged.

Depending on the characteristics (body dimensions) and properties (skin elongation) of each subject in the sample, bandages with different elongations must be applied to achieve the same strain in all of them and therefore produce the same effect.

Adapting the analysis offered by MRI, the dynamometer and other devices for the study of KT would facilitate the definition of protocols to carry out highly-important studies to promote understanding of the specific mechanisms of action of KTs, their real physiological effects and the possible clinical and sporting outcomes of their use.

\section{Acknowledgements}

The authors are grateful to the technicians of the Textile Physics Laboratory of the Polytechnic University of Valencia, Alcoy Campus, for the assignment of equipment and mechanical testing facilities.

The authors thank the technicians of the Central service of aid to experimental research at the University of Valencia for the assignment of equipment and facilities for the analysis by the gas chromatography of the tapes.

\section{Funding}

This study was not funded.

\section{Availability of data and materials}

The datasets used and/or analysed during the current study are available from the corresponding author on reasonable request.

\section{Authors' contributions}

FS: He made substantial contributions to conception and design, acquisition of data, analysis and interpretation of data. He made substantial contributions to conception and design, or acquisition of data, or analysis and interpretation of data. AP: He been involved in drafting the manuscript or revising it critically for important intellectual content. He made substantial contributions to conception and design. XA: He made substantial contributions to conception and design. He been involved in drafting the manuscript or revising it critically for important intellectual content. IM: He made substantial contributions to conception and design, acquisition of data and interpretation of data. LGS: been involved in drafting the manuscript or revising it critically for important intellectual content. Made substantial contributions to or analysis and interpretation of data. CB: been involved in drafting the manuscript or revising it critically for important intellectual content. Made substantial contributions to analysis and interpretation of data. All authors read and approved the final manuscript.

\section{Ethics approval and consent to participate}

Not applicable.

\section{Consent for publication}

Not applicable.

\section{Competing interests}

The authors declare that they have no competing interests.

\section{Publisher's Note}

Springer Nature remains neutral with regard to jurisdictional claims in published maps and institutional affiliations.

\section{Author details}

'Department of Physiotherapy, Own Master in evaluation, physiotherapy and reconditioning in sports science, University of Valencia, Calle Gascó Oliag 3, 46010 Valencia, Spain. ${ }^{2}$ School of Physical Activity and Sport Sciences,
University of Valencia, Calle Gascó Oliag 3, 46010 Valencia, Spain. ${ }^{3}$ Group of Human Biomechanics and Sports, University of Castilla-La Mancha, Avenida de Carlos III s/n, 45071 Toledo, Spain. ${ }^{4}$ Department of Textile and Paper Engineering, Valencia Polytechnic University, Plaza Ferrándiz y Carbonell, 1, 03801 Alcoy, Spain. ${ }^{5}$ Institute for Research on Musculoskeletal Disorders, School of Medicine, Valencia Catholic University, c/ Quevedo, 2, 46001 Valencia, Spain.

Received: 8 September 2017 Accepted: 26 March 2019

Published online: 09 April 2019

\section{References}

1. Fu TC, Wong AM, Pei YC, Chou SW, Lin YC. Effect of Kinesio taping on muscle strength in athletes-a pilot study. J Sci Med Sport. 2008;11:198-201. https://doi.org/10.1016/j.jsams.2007.02.011.

2. Jaraczewska $E$, Long C. Kinesio taping in stroke: improving functional use of the upper extremity in hemiplegia. Top Stroke Rehabil. 2006;13:31-42. https://doi.org/10.1310/33KA-XYE3-QWJB-WGT6.

3. Karatas N, Bicici S, Baltaci G, Caner H. The effect of Kinesiotape application on functional performance in surgeons who have musculo-skeletal pain after performing surgery. Turk Neurosurg. 2012;22:83-9. https://doi.org/10. 5137/1019-5149.JTN.5377-11.1.

4. Hagen L, Hebert JJ, Dekanich J, Koppenhaver S. The effect of elastic therapeutic taping on Back extensor muscle endurance in patients with low Back pain: a randomized, controlled, crossover trial. J Orthop Sports Phys Ther. 2015;45:215-9. https://doi.org/10.2519/jospt.2015.5177.

5. Lim ECW, Tay MGX. Kinesio taping in musculoskeletal pain and disability that lasts for more than 4 weeks: is it time to peel off the tape and throw it out with the sweat? A systematic review with meta-analysis focused on pain and also methods of tape application. Br J Sports Med. 2015;0:1-10. https://doi.org/10.1136/bjsports-2014-094151.

6. Nunes GS, Vargas VZ, Wageck B. Kinesio taping does not decrease swelling in acute, lateral ankle sprain of athletes: a randomised trial. J Physiother. 2015;61:28-33. https://doi.org/10.1016/j.jphys.2014.11.002

7. Thelen MD, Dauber JA, Stoneman PD. The clinical efficacy of kinesio tape for shoulder pain: a randomized, double-blinded, clinical trial. J Orthop Sports Phys Ther. 2008;38:389-95. https://doi.org/10.2519/jospt.2008.2791.

8. Williams S, Whatman C, Hume PA, Sheerin K. Kinesio taping in treatment and prevention of sports injuries. A meta-analysis of the evidence for its effectiveness. Sports Med. 2012;42:153-64. https://doi.org/10.2165/ 11594960-000000000-00000

9. Capecci M, Serpicelli C, Fiorentini L, Censi G, Ferretti M, Orni C, Renzi R, Provinciali L, Ceravolo MG. Postural rehabilitation and Kinesio taping for axial postural disorders in Parkinson's disease. Arch Phys Med Rehabil. 2014; 95:1067-75. https://doi.org/10.1016/j.apmr.2014.01.020.

10. Kase K, Wallis J, Kase T. Clinical therapeutic applications of the Kinesio taping method. 1st ed. Tokyo: Ken Ikai Co Ltd.; 2003.

11. Fayson SD, Needle AR, Kaminski TW. The effects of ankle Kinesio ${ }^{\circledR}$ taping on ankle stiffness and dynamic balance. Res in Sports Med. 2013;(3):204-16. https://doi.org/10.1080/15438627.2013.792083.

12. Bassett $K$, Lingman $S$, Ellis R. The use and treatment effcacy of kinaesthetic taping for musculoskeletal conditions: a systematic review. N Z J Physiother. 2010;38:56-60.

13. Kalron A, Bar-Sela S. A systematic review of the effectiveness of Kinesio taping -fact or fashion? Eur J Phys Rehabil Med. 2013;49:699-709.

14. Morris D, Jones D, Ryan H, Ryan CG. The clinical effects of Kinesio ${ }^{\oplus}$ Tex taping: a systematic review. Physio Theory Practice. 2013;29:259-70. https:// doi.org/10.3109/09593985.2012.731675.

15. Mostafavilar M, Wertz J. A systematic review of the effectiveness of Kinesiotaping for musculoskeletal injury. Phys Sportsmed. 2012;40:33-40. https://doi.org/10.3810/psm.2012.11.1986.

16. Parreira PC, Costa LC, Hespanhol Junior LC, Lopes AD, Costa LO. Current evidence does not support the use of Kinesio taping in clinical practice: a systematic review. J Physiother. 2014;60:31-9. https://doi.org/10.1016/j.jphys. 2013.12.008

17. Added MA, Costa LO, de Freitas DG, Fukuda TY, Monteiro RL, Salomao EC, de Medeiros FC, Costa Lda C. Kinesio taping does not provide additional benefits in patients with chronic low Back pain who receive exercise and manual therapy: a randomized controlled trial. J Orthop Sports Phys Ther. 2016;46:506-13. https://doi.org/10.2519/jospt.2016.6590. 
18. Guyatt GH, Oxman AD, Schunemann HJ, Tugwell P, Knottnerus A. GRADE guidelines: a new series of articles in the journal of clinical epidemiology. $J$ Clin Epidemiol. 2011;64:380-2. https://doi.org/10.1016/j.jclinepi.2010.09.011.

19. Poon KY, Li SM, Roper MG, Wong MKM, Wong O, Cheung RTH. Kinesiology tape does not facilitate muscle performance: a deceptive controlled trial. Man Ther. 2014:1-4. https://doi.org/10.1016/j.math.2014.07.013.

20. Espejo L, Apolo MD. Revisión bibliográfica de la efectividad del kinesiotaping. Rehabilitación. 2011;45:148-58. https://doi.org/10.1016/j.rh. 2011.02.002

21. Pamuk U, Yucesoy CA. MRI analyses show that kinesio taping affects much more than just the targeted superficial tissues and causes heterogeneous deformations within the whole limb. J Biomech. 2015;48:4262-70. https:// doi.org/10.1016/j.jbiomech.2015.10.036.

22. Fernández Rodríguez JM, Alegre Durán LM, Abián Vicén J, Carcelén Cobo R, Aguado Jódar X. Vendaje neuromuscular: ¿tienen todas las vendas las mismas propiedades mecánicas? Apunts Med Esport. 2010;45:61-7. https:// doi.org/10.1016/j.apunts.2009.11.001.

23. Matheus JPC, Zille RR, Gomide LB, Lemos TV, Carregaro RL, Shimano AC. Comparison of the mechanical properties of therapeutic elastic tapes used in sports and clinical practice. Phys Ther in Sports. 2017;24:74-8. https://doi. org/10.1016/j.ptsp.2016.08.014.

24. ISO 9856:2003/Amd 1 (2012). Conveyor belts-Determination of elastic and permanent elongation and calculation of elastic modulus. https://www.une. org/encuentra-tu-norma/busca-tu-norma/norma?c=N0050287. Accessed 2015.

25. ISO 139:2005/AMD 1. (2011). Textiles-Standard atmospheres for conditioning and testing-Amendment 1. https://www.iso.org/obp/ui/\#iso:std:iso:13934:-1: ed-2:v1:en. Accessed 2015.

26. ISO 13934-1, Technical Committee ISO/TC 38. (2013). Textiles, Subcommittee SC 24, Conditioning atmospheres and physical tests for textile fabrics. https://www.iso.org/obp/ui/\#iso:std:iso:13934:-1:ed-2:v1:en. Accessed 2015.

27. ISO 3696:1996. Water for analytical laboratory use. Specification and methods. https://www.une.org/encuentra-tu-norma/busca-tu-norma/norma/ ?c=N0013433. Accessed 2015

28. UNE 59511-1:2007. Footwear. Materials for uppers, lining and insocks. Determination of heavy metals content extractable by acid perspiration solution in textile materials for footwear. Part 1: Determination of $\mathrm{Cd}, \mathrm{Ni}, \mathrm{Cr}$, $\mathrm{Co}, \mathrm{Pb}, \mathrm{Sb}$ and $\mathrm{Cu}$. https://www.une.org/encuentra-tu-norma/busca-tunorma/norma/?c=N0038260\#.WDrKOHdDmb9. Accessed 2015.

29. Lewis JS, Wright C, Green A. Subacromial impingement syndrome: the effect of changing posture on shoulder range of movement. J Orthop Sports Phys Ther. 2005;35:72-87. https://doi.org/10.2519/jospt.2005.35.2.72.

30. Bravi R, Quarta E, Cohen EJ, Gottard A, Minciacchi D. A little elastic for a better performance: kinesiotaping of the motor effector modulates neural mechanisms for rhythmic movements. Front Syst Neurosci. 2014;8:181. https://doi.org/10.3389/fnsys.2014.00181.

31. Chang HY, Chou KY, Lin JJ, Lin CF, Wang CH. Immediate effect of forearm Kinesio taping on maximal grip strength and force sense in healthy collegiate athletes. Phys Ther in Sport. 2010;11:122-7. https://doi.org/10. 1016/j.ptsp.2010.06.007.

32. Lee MH, Lee CR, Park JQ, Lee SY, Jeong TG, Son GS, Lee JY, Kim EC, Kim YK Influence of Kinesio taping on the motor neuron conduction velocity. J Phys Ther Scie. 2011;23:313-5. https://doi.org/10.1589/jpts.23.313.

33. Chen WC, Hong WH, Huang TF, Hsu HC. Effects of kinesio taping on the timing and ratio of vastus medialis obliquus and vastus lateralis muscle for person with patellofemoral pain. J Biomech. 2007;40:318. https://doi.org/10. 1016/S0021-9290(07)70314-7.

34. Lee $\mathrm{CR}$, Lee DY, Jeong HS, Lee MH. The effects of Kinesio taping on VMO and VL EMG activities during stair ascent and descent by persons with patellofemoral pain: a preliminary study. J Phys Ther Scie. 2012;24:153-6. https://doi.org/10.1589/jpts.24.153.

35. Saavedra-Hernandez M, Castro-Sanchez AM, Arroyo-Morales M, Cleland JA, Lara-Palomo IC, Fernandez-de-Las-Penas C. Short-term effects of kinesio taping versus cervical thrust manipulation in patients with mechanical neck pain: a randomized clinical trial. J Orthop Sports Phys Ther. 2012;42:724-30. https://doi.org/10.2519/jospt.2012.4086.

36. Sijmonsma J. Manual taping neuro muscular. 1st ed. Cascais: Aneid Press; 2007. p. 200

37. Vercelli S, Colombo C, Tolosa F, Moriondo A, Bravini E, Ferriero G, Francesco $\mathrm{S}$. The effects of kinesio taping on the color intensity of superficial skin hematomas: a pilot study. Phys Ther in Sport. 2017;23:156-61. https://doi. org/10.1016/j.ptsp.2016.06.005.

38. Oliveira A, Borges D, Lins C, Cavalcanti R, Macedo L, Brasileiro J. Immediate effects of Kinesio taping ${ }^{\oplus}$ on neuromuscular performance of quadriceps and balance in individuals submitted to anterior cruciate ligament reconstruction: a randomized clinical trial. J Sci Med Sport. 2016;19:2-6. https://doi.org/10.1016/j.jsams.2014.12.002.

39. González-Iglesias J, Fernández-de-Las-Peñas C, Cleland JA, Huijbregts P, Del Rosario MGV. Short-term effects of cervical kinesio taping on pain and cervical range of motion in patients with acute whiplash injury: a randomized clinical trial. J Orthop Sports Phys Ther 2009; 39: 515-521. doi: https://doi.org/10.2519/jospt.2009.3072.
Ready to submit your research? Choose BMC and benefit from:

- fast, convenient online submission

- thorough peer review by experienced researchers in your field

- rapid publication on acceptance

- support for research data, including large and complex data types

- gold Open Access which fosters wider collaboration and increased citations

- maximum visibility for your research: over $100 \mathrm{M}$ website views per year

At BMC, research is always in progress.

Learn more biomedcentral.com/submissions 